\title{
Venture capitalists' decision-making in small equity markets: a case study using participant observation
}

\author{
JORGE SILVA
}

(Final version accepted 13 February 2004)

\begin{abstract}
Despite significant academic research undertaken in the field of venture capital decisionmaking process, the dimension and maturity of equity market has not yet been considered as an important contextual factor. Aiming at developing an understanding on how venture capitalists (VCs) select early-stage projects in small equity markets, a pilot study using participant observation technique has been conducted in a Portuguese venture capital firm. The findings indicate that the decision-making process and the criteria used by VCs in this market context differ significantly from those used in the developed equity markets. Regarding the decision-making process as a whole, it appears to be more interactive than usually portrayed in previous models. Moreover, some of the activities take place simultaneously, rather than sequentially. In particular, relevant differences were found in deal origination, deal evaluation and closing phase. Regarding the decision-making criteria applied, the findings of this case study are in accordance to previous studies and suggest that the attention of VCs is very focused on entrepreneur(s). The business idea, its sustainable advantages and growth potential are also considered important but, contrarily to previous literature, financial projections do not seem to play a major role in the selection of earlystage projects.
\end{abstract}

Keywords: decision-making process; venture capital; small equity markets; participantobservation

\section{Introduction}

Describing and understanding the venture capitalists' decision-making process has been the goal of a large number of academic researchers since the 1970s. The interest in this particular topic is bound to a variety of purposes: from verifying 'whether venture capital market allocates resources properly' (Fried and Hisrich 1994: 28), to helping venture capitalists to better understand their own decision making process, which, in turn, provides the opportunity to increase evaluation efficiency (Shepherd 1999), to aiding entrepreneurs in obtaining funds (Timmons and Gumpert 1982).

Despite significant academic research undertaken in the field of venture capitalists decision-making process, the maturity of private equity market

Forge Silva is a lecturer at the Faculty of Economics, University of Porto, Portugal, and a PhD Student at the School of Business and Economics, University of Jyväskylä, P.O. Box 35, 40014 Jyräskylä, Finland. His research interest is in entrepreneurial finance; e-mail: silva@econ.jyu.fi 
as an important contextual factor has not yet been considered. Aimed at developing an understanding on how venture capitalists (VCs) select earlystage investments in small equity markets, this article reports on the findings of an exploratory project that analyses the VCs' decision-making process of a Portuguese venture capital firm (VCF). The article proceeds as follows: first, the literature on VCs decision-making process is reviewed. Then, the limitations of previous studies are presented. Thereafter, the methodology adopted is explained, followed by the description of the case. Finally, results of the pilot study are presented and discussed.

\section{Research on venture capitalists' decision-making process}

The existing research on VCs' decision-making process can be classified into two broad streams: one is processual research-i.e. research focusing on the course of events and activities that constitute the VCs' decision-making process (e.g. Wells 1974, Tyebjee and Bruno 1984, Silver 1985, Hall 1989) - and the other is criteria research, i.e. research focusing on the criteria used by VCs when assessing proposals (e.g. Poindexter 1976, MacMillan et al. 1985, Khan 1987). While most of the studies can be positioned within one or the other research stream, some represent a combination of the two, having produced models outlining the phases of the decision-making process and the criteria used in each phase (e.g. Wells 1974, Boocock and Woods 1997). Table 1 summarizes some of the previous studies published in this area of research.

The processual stream of research initiated with the study by Wells (1974) has produced several models aiming at describing the decisionmaking process. Table 2 presents the various phases of investment process identified in these studies. As referred by Hall and Hofer (1993: 29) the most relevant facts revealed by the studies and agreed by all the researchers are: (1) that the process consists in multiple phases and (2) that the venture evaluation itself involves at least two phases - screening and evaluation.

With regard to criteria research, there is significant number and variety of studies. The first wave of studies focused on asking VCs for criteria commonly used in assessing proposals. As a result, a weighted list (Wells 1974) or a ranked list (e.g. Poindexter 1976) of criteria was obtained. Wells (1974) found that VCs consider management commitment as the criterion having the highest weight in assessment of proposals. This criterion was closely followed by product, market and marketing skills. The results of Poindexter's study identify the quality of management as the criterion with the highest rank in the opinion of VCs followed by expected rate of return and expected risk. Tyebjee and Bruno (1981) found management skills as the most important factor. The study by MacMillan et al. (1985) reveals that five of 10 most important criteria were related to entrepreneur's experience or personality.

Since that first wave of studies on VCs' decision-making process, a significant number of subsequent studies have enriched the existing knowledge by using different methodological approaches. One group of researchers have conducted studies that attempted to validate the VCs' 


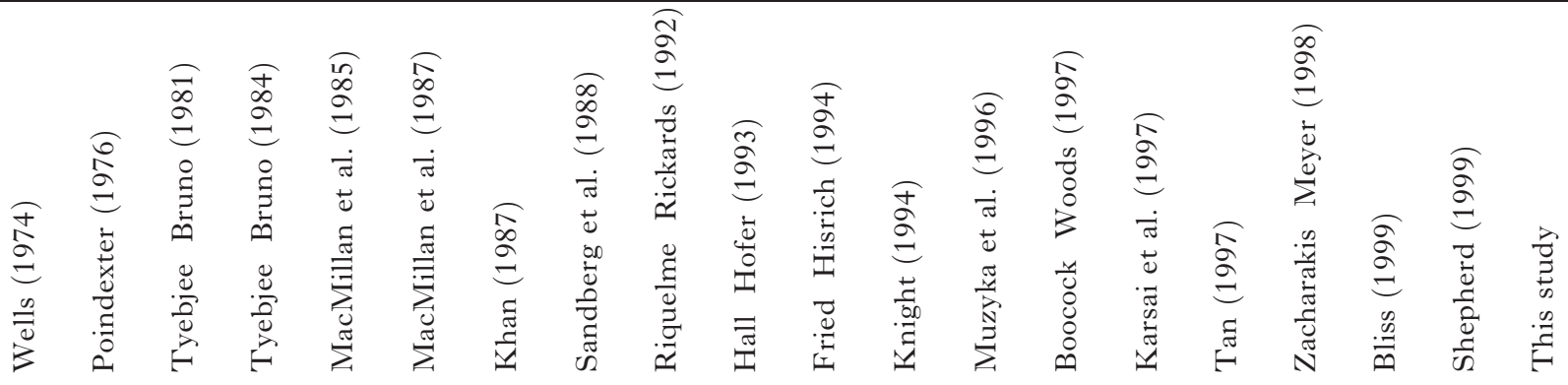

\section{Type of research}

Criteria research

Processual Research

\section{Sample size}

$\mathrm{VCF}$

$\mathrm{VCs}$

Investments

Proposals/applications

$\mathrm{X} \quad \mathrm{X}$

Profiles

$\begin{array}{ll}\mathrm{X} & \mathrm{X} \\ \mathrm{X} & \end{array}$

X

$8 \quad 97$

46

Type of proposals assessed

None in specific

Proposals under consideration

Successful investments

Unsuccessful investments

Hypothetical ventures

Context of the study

Developed equity market

Cross-national comparison

Transition economy

Emerging equity market

Small equity market 


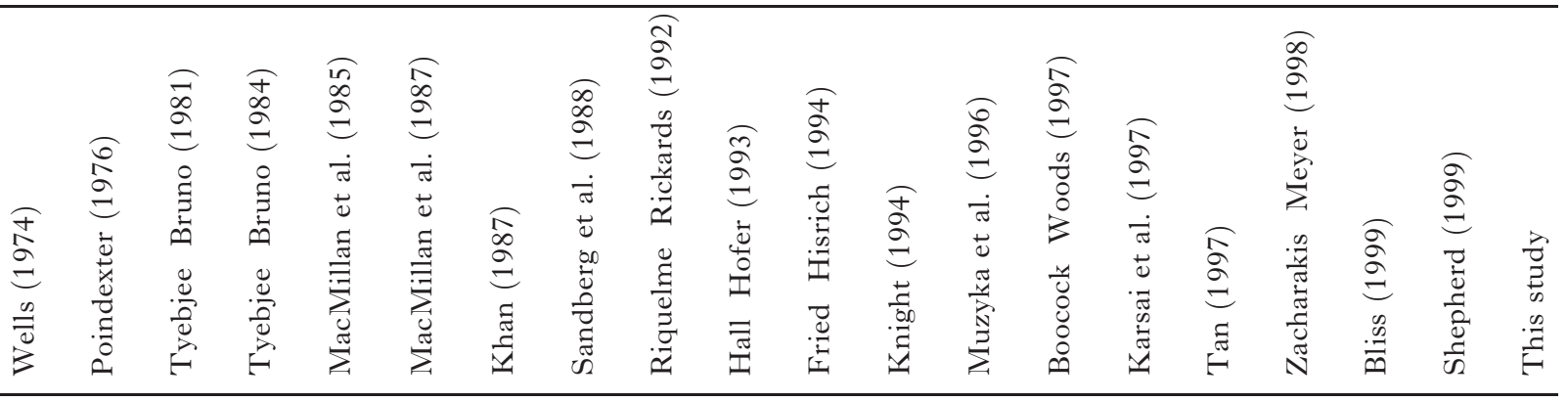

\section{Data gathering method}

Interviews

Questionnaires

Archival records search

Verbal protocols

Experiment (full profile)

Experiment (trade-offs)

Participation observation

Data analysis method

Descriptive statistics

Content analysis

Factor analysis

Discriminant analysis

Cluster analysis

Conjunctive modelling

Disjunctive modelling

Regression analysis

Conjoint analysis

nalysis

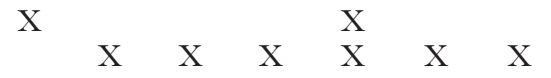

$\mathrm{X}$

$\begin{array}{ll}\mathrm{X} \\ \mathrm{X} \\ \mathrm{X} & \mathrm{X}\end{array}$

$\begin{array}{cccccc}\mathrm{X} & \mathrm{X} & \mathrm{X} & \mathrm{X} & \mathrm{X} & \mathrm{X} \\ \mathrm{X} & & \mathrm{X} & & & \\ & & & \mathrm{X} & \mathrm{X} & \mathrm{X} \\ & & & \mathrm{X} & & \\ & & & & \mathrm{X} & \mathrm{X}\end{array}$

X

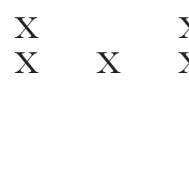

$\mathrm{X}$

X

$\begin{array}{ll}\mathrm{X} & \\ \mathrm{X} & \end{array}$

$\mathrm{X}$
$\mathrm{X}$

X

X

$\mathrm{X} \quad \mathrm{X}$

X

$\begin{array}{ll} & \\ \mathrm{X} & \\ \mathrm{X} & \\ & \mathrm{X} \\ & \\ & \\ & \end{array}$

$\begin{array}{lll} & \mathrm{X} & \mathrm{X} \\ \mathrm{X} & \mathrm{X}\end{array}$

$\begin{array}{lll}\mathrm{X} & \mathrm{X} & \mathrm{X} \\ \mathrm{X} & & \end{array}$

$\mathrm{X}$
$\mathrm{X}$

$\mathrm{X}$

X

$\begin{array}{llll}\mathrm{X} & \mathrm{X} & \mathrm{X}\end{array}$


Table 2. Models of investment process in VCFs

\begin{tabular}{|c|c|c|c|c|c|}
\hline $\begin{array}{l}\text { Wells } \\
(1974)\end{array}$ & $\begin{array}{c}\text { Tyebjee and } \\
\text { Bruno (1984) }\end{array}$ & $\begin{array}{c}\text { Hall } \\
(1989)\end{array}$ & $\begin{array}{c}\text { Fried and } \\
\text { Hisrich (1994) }\end{array}$ & $\begin{array}{l}\text { Boocock and } \\
\text { Woods (1997) }\end{array}$ & $\begin{array}{l}\text { Bliss } \\
(1999)\end{array}$ \\
\hline $\begin{array}{l}\text { Search for } \\
\text { investment }\end{array}$ & $\begin{array}{c}\text { Deal } \\
\text { origination }\end{array}$ & $\begin{array}{l}\text { Generating a } \\
\text { deal flow }\end{array}$ & $\begin{array}{c}\text { Deal } \\
\text { origination }\end{array}$ & $\begin{array}{l}\text { Generating a } \\
\text { deal flow }\end{array}$ & Origination \\
\hline \multirow{2}{*}{$\begin{array}{l}\text { Screening of } \\
\text { proposals }\end{array}$} & \multirow{2}{*}{ Screening } & $\begin{array}{l}\text { Proposal } \\
\text { screening }\end{array}$ & $\begin{array}{c}\text { Firm-specific } \\
\text { screen }\end{array}$ & $\begin{array}{c}\text { Initial } \\
\text { screening }\end{array}$ & \multirow{2}{*}{ Generic screen } \\
\hline & & $\begin{array}{c}\text { Proposal } \\
\text { assessment }\end{array}$ & Generic screen & First meeting & \\
\hline \multirow{4}{*}{$\begin{array}{l}\text { Evaluation of } \\
\text { proposals }\end{array}$} & \multirow{3}{*}{ Evaluation } & \multirow{2}{*}{$\begin{array}{c}\text { Project } \\
\text { evaluation }\end{array}$} & \multirow{2}{*}{$\begin{array}{l}\text { First phase } \\
\text { evaluation }\end{array}$} & $\begin{array}{l}\text { Second } \\
\text { meeting }\end{array}$ & \multirow{2}{*}{$\begin{array}{l}\text { First-phase } \\
\text { evaluation }\end{array}$} \\
\hline & & & & $\begin{array}{c}\text { Board } \\
\text { presentation }\end{array}$ & \\
\hline & & Due diligence & $\begin{array}{c}\text { Second phase } \\
\text { evaluation }\end{array}$ & Due diligence & $\begin{array}{c}\text { Second phase } \\
\text { evaluation }\end{array}$ \\
\hline & $\begin{array}{c}\text { Deal } \\
\text { structuring }\end{array}$ & $\begin{array}{c}\text { Deal } \\
\text { structuring }\end{array}$ & Closing & $\begin{array}{c}\text { Deal } \\
\text { structuring }\end{array}$ & Closing \\
\hline
\end{tabular}


selection criteria. MacMillan et al. (1987) represents one of the first attempts to test, if the criteria identified in previous studies (mainly in MacMillan et al. 1985) were indeed helpful to distinguish between successful and unsuccessful ventures. An important finding of their study, identified through regression analysis, was that the two major criteria predictors of venture success are: '(1) the extent to which the venture is initially insulated from competition and (2) the degree to which there is demonstrated market acceptance of the product' (MacMillan et al. 1997: 124). Khan (1987) also conducted research in this area, but adopted a different approach. He used two types of non-compensatory actuarial models-conjunctive and disjunctive - to model both VCs' judgement and the environment (the actual outcome of ventures). The results showed that VCs give emphasis to the entrepreneurs' desire to succeed and the uniqueness of the product as essential variable in arriving at their judgement. 'This study also suggests that VCs' judgements are poor predictors of actual outcomes and that derived models outperform VCs' judgements.

Another group of researchers have applied real-time data gathering methods to solve the possible introspection biases associated with the methods used in previous studies. One of the methods introduced was verbal protocols, a method that consists in asking the research participants to 'think aloud', i.e. verbalize their thoughts as they perform a particular task (see Ericsson and Simon 1984). Sandberg et al. (1988) tested the applicability of this method in one VCF. Hall and Hofer (1993) conducted a more extensive verbal protocol research with four VCF and 16 protocols. The results of this study suggested that in the initial proposal screening, the most important criteria were the fit with the venture firm's lending policy and the long term growth and profitability of the industry. In the next phase of the proposal assessment, the source of the business proposal was also considered important. Contrarily to the previous findings, this study suggested that VCs do not attribute significant importance to the entrepreneur(s) and the business strategy, at least not in the early phases of the decisionmaking process.

The other real-time data gathering method used in recent studies is experiments. This method was essentially used to collect data in order to perform conjoint analysis (e.g. Riquelme and Rickards 1992, Muzyka et al. 1996, Shepherd 1999). The goal of conjoint analysis is to capture quantitatively the relative importance of a list of attributes set against each other (Muzyka et al. 1996: 276). Riquelme and Rickards (1992) in their study confirmed the emphasis VCs placed on the entrepreneur's experience. A subsequent study conducted by Muzyka et al. (1996) used a variation of the same technique (tradeoffs) to analyse 35 criteria and found that all five management team criteria were positioned in the top of the ranking. These criteria were (1) leadership potential of the lead entrepreneur; (2) leadership potential of the management team; (3) existence of recognized industry expertise in team; (4) track record of the lead entrepreneur and (5) track record of the management team. 


\section{Limitations of previous studies}

The previous studies revised above present two types of major limitations in uncovering the VCF's decision-making process: the first is bound to data collection methods adopted, while the second is associated with the research context where those studies were conducted. Regarding data collection methodology, as referred by several authors (Sandberg et al. 1988, Hall and Hofer 1993, Shepherd 1999), most of the existing studies present limitations associated with retrospective reporting (e.g. Tyebjee and Bruno 1984), questionnaire responses rather than actual evaluations (e.g. Poindexter 1976, MacMillan et al. 1985), and self-reporting (e.g. MacMillan et al. 1987). Some studies have attempted to address these problems by using alternative approaches to gather empirical evidence, e.g., taping verbal protocols (see, Sandberg et al. 1988, Hall and Hofer 1993), searching out private documents of the firm (Boocock and Woods 1997) or conducting experiments (e.g. Zacharakis and Meyer 1998). Despite their significant contribution, these approaches remain limited. In the case of verbal protocols, the limitation concerns reliance only on selfreported data. In the case of archival search, its limitation results from the fact that it captures only the outputs of the process. The experiments as a methodological approach is also limited, in particular, due to the fact that it relies on hypothetical ventures and environments, rather than on actual proposals, and uses previously defined, therefore restricted, number of attributes to be assessed by the VCs.

Regarding the research context, while most of the past studies have analysed the VCs' decision-making process in large and developed private equity markets, only a very limited number of studies have explored the topic in countries where the private equity industry remains small, i.e., where the private equity market does not yet represent a visible alternative source for financing companies. The only study on this topic that has gone beyond merely identifying the criteria used by VCs in such type of market was carried out by Bliss (1999) and aimed at assessing the impact of economic context (a transition economy), rather than the influence of the dimension and maturity of the private equity market on VCs' decisionmaking process. While the results of Bliss's study clearly reveal processual differences between the decision-making process of VCs in Poland as compared to that described in previous processual studies (Wells 1974, Tyebjee and Bruno 1984, Hall 1989, Fried and Hisrich 1994, Boocock and Woods 1997), given the implicit assumption of his study, Bliss concludes that all these differences result from the particular economic context of a transition economy.

In order to understand the importance of the industry context it, therefore, appears to be necessary to proceed with an exploratory research on the VCs' decision-making process in the context of small equity markets. Given that most European countries have small private equity markets, the analysis of the influence of industry context on VCs' decisionmaking process could contribute importantly to generating more comprehensive knowledge to the research field. This study represents an attempt to address this issue. 


\section{Methodology}

Adopting the definition of process proposed by Pettigrew (1997: 338), this study aimed at capturing the 'sequence of individual and collective events, actions, and activities unfolding over time in context'. The goal of this exploratory study, thus, was to capture the VCs' decision-making process in the context of small equity market from a processual perspective.

Given that the characteristics of a venture vary by stage of development (Ruhnka and Young 1987, Fried and Hisrich 1994), the attention of this study was concentrated on early-stage proposals. ${ }^{1}$ Moreover, interested in generating knowledge to assist entrepreneurs in obtaining funds, this study focuses on the first phase in the VCs' decision-making cycle, namely, the investment process.

An instrumental case study (see Stake 1995) was used to develop understanding of whether or not the maturity of the equity market exerts an influence on the VCs' decision-making process. The case study methodology was chosen to capture rich informational content regarding the decision-making process, overcoming the limitations of other methodological approaches, namely, questionnaires, interviews and experiments used in the previous studies.

The main technique used for gathering empirical evidence in this exploratory case study was participant observation, a qualitative method that requires the researcher to become a participant in the culture and the context that he/she observes. The method consists in gathering 'data by participating in the daily life of the group or organization' studied and, as well as watching the people in the 'situations they ordinarily meet', entering into 'conversations with some or all of the participants in these situations' and discovering 'their interpretations of the events' observed (Becker 1958: 652). The purpose of the participant-observer, living for an extended period of time in a certain context (in order to become accepted as a part of the community), is to ensure that the observations register the phenomenon in its natural occurrence. In this particular field study, the focus was on capturing the events, activities and outputs associated with the decisionmaking process of venture capitalists as well as the criteria used along the process to assess the proposals (see Jorgensen 1989).

The main difference between participant observation and the methods applied in previous studies is that the data gathered with this method combines a real-time, holistic and dynamic view on the decision-making process of $\mathrm{VCs}$ in its natural occurrence. It provides a real-time view in the sense that the information is gathered in the moment it happens. It is holistic because this method enables gathering information from the various players-VCs, entrepreneurs, experts, support staff-involved in the decision-making process. It is dynamic because it generates information on the interactions between the various players as well as provides insights on the sequence of activities and events along the process itself. Therefore, this method has the advantage of minimizing the problems associated with the majority of past research, namely the retrospective and self-reporting biases associated with ex-post interviews and questionnaires and the reductionism associated with experiments. Participant observation has also 
the advantage when compared to verbal protocol technique, because it permits gathering the information in its natural occurrence rather than in a controlled environment.

As referred by Jorgensen (1993: 45) there are two basic strategies to gaining access to phenomena of interest when using participant observation technique. When the researcher openly requests permission to observe, the strategy is called overt. When that is not the case, the strategy is then named covert. The strategy chosen in this study was overt. In this research, the application to participate and observe was made directly to the CEO of the company with a short description of the research project and a proposal to do participant observation research. After a preliminary approval I was invited to present the research project to the board of directors. At the end of this meeting, after guaranteeing the confidentiality of the players and proposals involved, the access was granted. It was agreed that I would conduct the participant observation research over a 4 month period, acting as assistant to an investment analyst, with authorization to assist in meetings and interview the personnel with the aim of collecting information concerning the VCs' decision-making process when selecting early-stage projects.

During this period of time, I observed the daily routines and carried informal discussions with the personnel, in particular, with investment analysts and executives. I also analysed the information provided by the entrepreneurs, the internal reports, contractual agreements, press releases and personal notes of the investment analysts, as well as the official company reports. Complementarily, I was granted the opportunity to observe the meetings between representatives of the VCF and entrepreneurs, the weekly company meetings and the executive meetings in which the early-stage projects were analysed. To finalize the evidence collection process, I conducted a standardized open-end interview with each senior

Table 3. Proposals in study

\begin{tabular}{llll}
\hline Proposal & Sector* & Financing stage & Decision \\
\hline 1 & Industrial Products & Seed & Under analysis \\
2 & Consumer Related & Start-up & Under analysis \\
3 & Computer Related & Start-up & Under analysis \\
4 & Materials & Seed & Internal Decision to invest \\
5 & Computer Related & Seed & Rejected \\
6 & Services & Start-up & Rejected \\
7 & Computer Related & Start-up & Under analysis \\
8 & Consumer Related & Start-up & Rejected \\
9 & Consumer Related & Start-up & Rejected \\
10 & Biotechnology & Start-up & Rejected \\
11 & Services & Start-up & Rejected \\
12 & Services & Start-up & Rejected \\
13 & Services & Start-up & Rejected \\
14 & Services & Start-up & Rejected \\
15 & Services & Start-up & Rejected \\
16 & Services & Start-up & Under analysis \\
\hline
\end{tabular}

*The classification of sectors follows the one of the European Venture Capital Association (EVCA). 
executive and investment analyst of the VCF. Appendix 1 compiles the sources of evidence used in this case study.

During the field study, I collected relevant data rather openly, taking field notes with a pen and notebook. When that was not possible, I waited until I could return to my desk to write down the observations, conversations and feelings experienced. In addition to this, I photocopied or saved (in electronic format) various documents and audio recorded the formal interviews conducted with the investment analysts and executives.

\section{Case study}

The firm chosen for this instrumental case study is one of the first VCFs in Portugal. Launched in the late 1980s, the company is responsible for management of four funds, with a total of more than 100 million euros for venture capital investment. Its major investor is a public institute, other relevant investors being major Portuguese financial groups.

Currently the VCF manages a portfolio of more than 50 companies in several sectors and different regions of the country. It has invested an average of 400000 euros per portfolio company in exchange for a minority position in their equity. From a team of more than 20 collaborators, three senior executives, three senior investment analysts, and three junior investment analysts are directly involved in the decision-making process of the VCF.

\section{Results and discussion}

The evidence presented here was gathered during the four months (September to December 2002) of the field study, and concerns the decision-making process regarding 16 early-stage proposals. Table 3 provides a brief description of the proposals by sector, stage of financing and decision reached. At the time when the field study was initiated, four of the 16 early-stage proposals were already under analysis. At the end of the observation period, six proposals where still undergoing analysis (one with an internal decision to invest). The investments expected for the proposals studied range in size from 50000 euros to 2.5 million euros.

As the data was being gathered the information was classified by source of evidence and compiled by proposal. The codes used to classify the sources of evidence were $\mathrm{O}$ (observations), I (interviews) and D (documents). After the field study was completed and the interviews transcribed, the data analysis was initiated with a content analysis of the evidence gathered. During this analysis the activities, events and criteria identified were also coded. The codes used for the classification were A (activity), E (event), CE (criteria regarding the entrepreneur), CB (criteria regarding the business idea), CM (criteria regarding the market), CD (criteria regarding the deal) and CO (other criteria).

The activities and events that became salient are listed in Appendix 2. This appendix presents the type of evidence gathered from each specific 
1.

2.
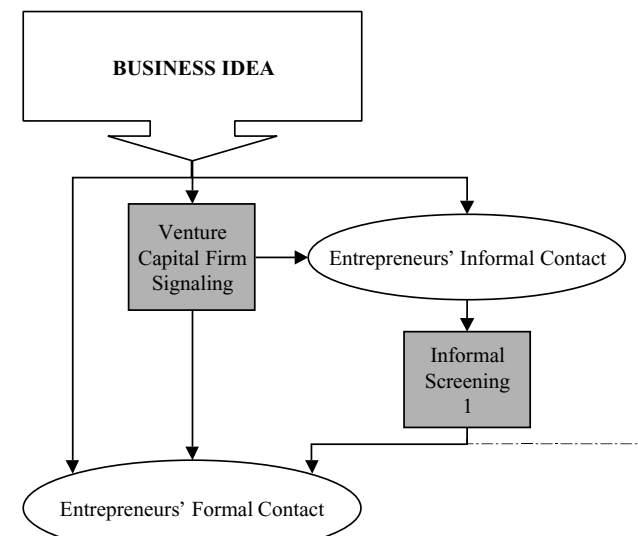

3.

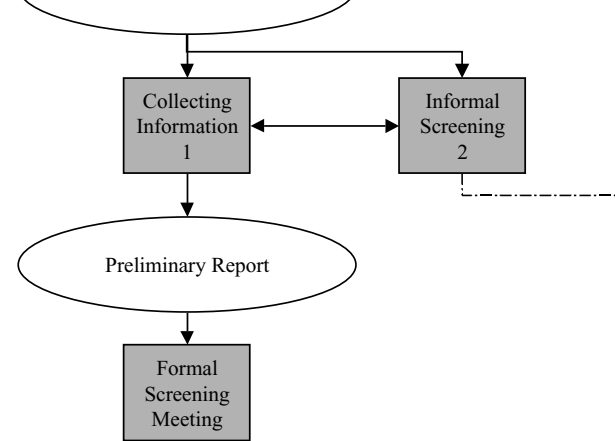

4.

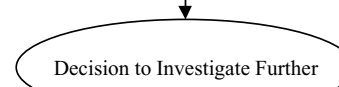

5.

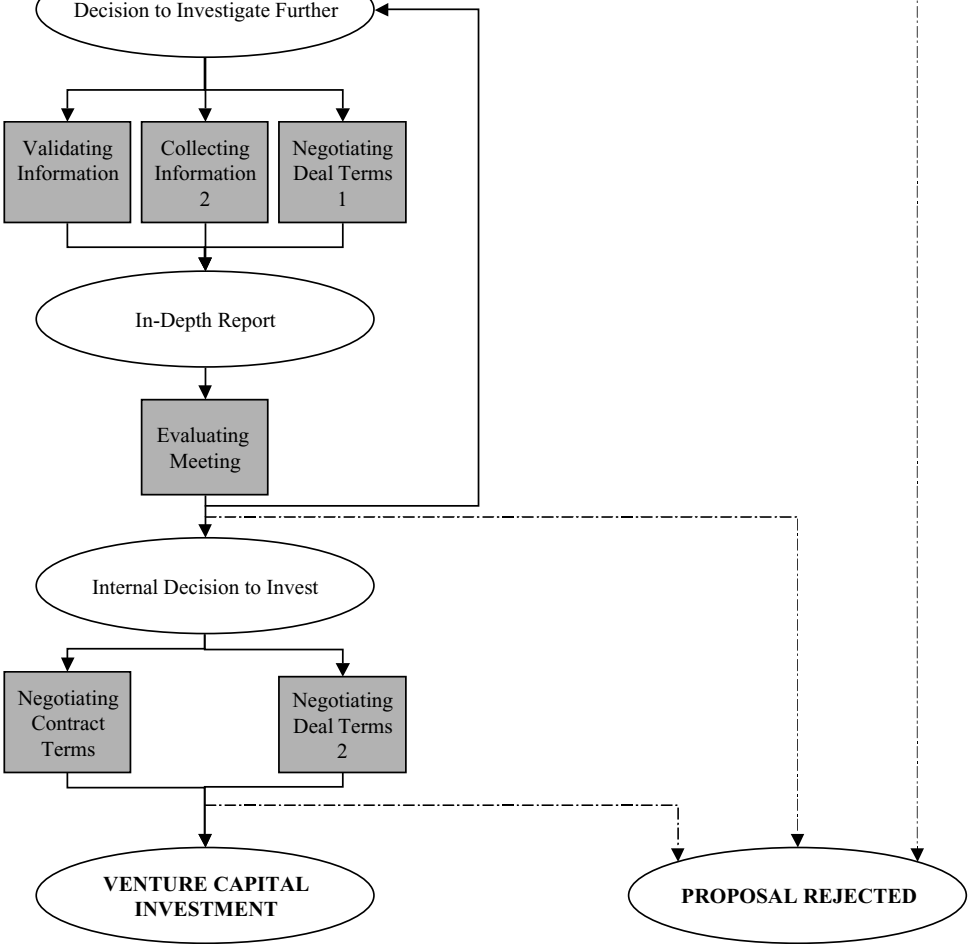

Figure 1. Investment process in the venture capital firm 


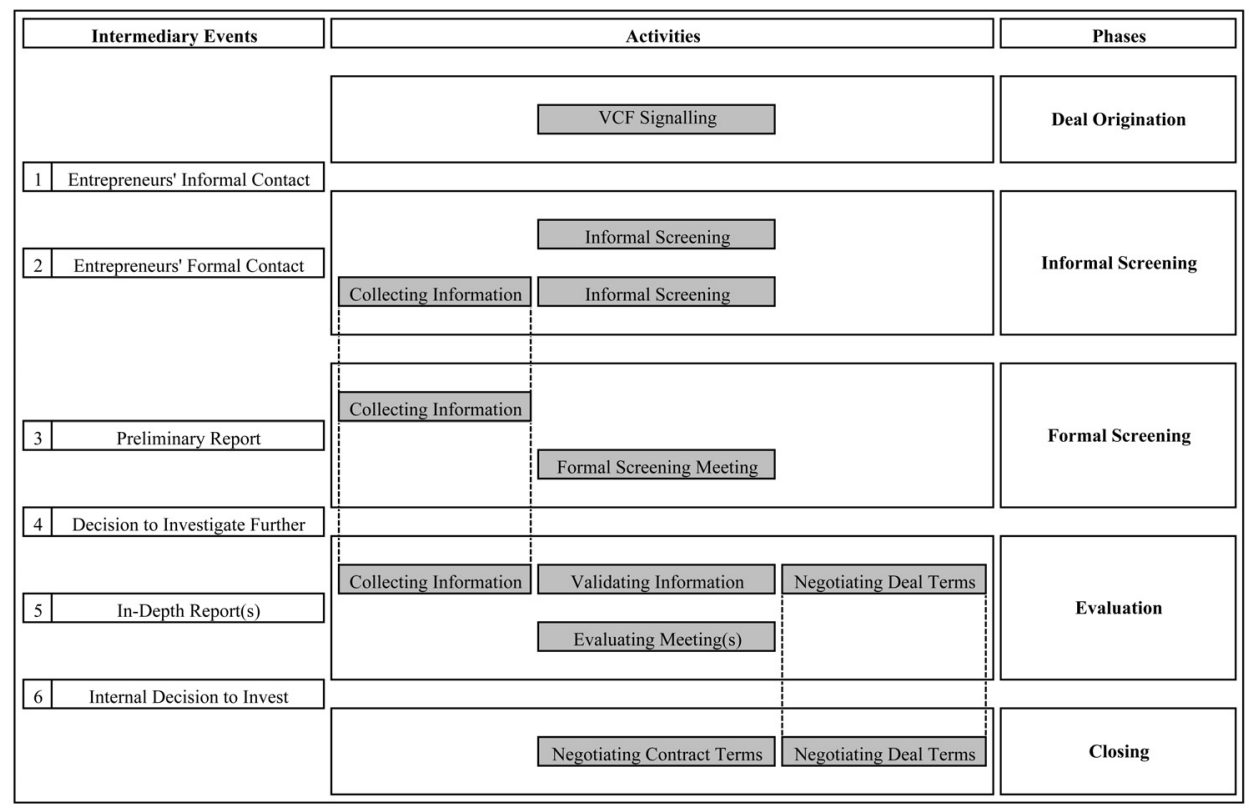

Figure 2. Activities, events and phases of the investment process

proposal that contributed to uncover these activities and events. The decision-making criteria identified are compiled in Appendix 3. It specifies the proposals and phases in which each criterion was assessed.

As a result of the analysis of the evidence gathered concerning the decision-making process of $\mathrm{VCs}$ with regard to the business proposals analysed, a visual representation of the investment process of the VCF was elaborated. Figure 1 represents the process from the entrepreneur's business idea until the VCF decision to invest or to reject the proposal. It includes all the relevant activities carried out by the VCs, as well as the six intermediary events identified and the two final events possible (venture capital investment or proposal rejection). In this figure, a square depicts an activity performed in order to achieve a particular aim, while an ellipse represents an event, i.e. a rather momentary occurrence, an outcome of one or more activities.

Compared to the models of VCs' decision-making process encountered in the previous literature, significant differences where found with regard to both, the process and the criteria applied. These differences are highlighted with a special emphasis on those that may be explained as resulting from the dimension and maturity of equity market. Some of the differences further discussed refer to the structure and dynamics of the decision-making process, while the others are associated with a specific stage. In order to facilitate the comparison of this model with those developed in the past, figure 2 presents how the various activities and events identified here could be converted into phases. The observations during the field study suggest that the decision-making process is more 
interactive than the existing models generally depict. Moreover, some of the activities in the various phases of decision-making process may occur simultaneously, rather than sequentially.

In the previous literature, interaction between the $\mathrm{VCF}$ and the entrepreneur(s) is portrayed as taking place only after the proposals have successfully gone through the (formal) screening phase. However, in the field study the first interaction often took place in the very beginning of the process. For instance, VCF's representatives were approached by the entrepreneurs in a public presentation or were contacted by mail or by phone for a meeting. During the field study, eight out of 12 new proposals were initiated by entrepreneurs' informal contact with the VCF. These early interactions are used by both the entrepreneur(s) and the VCs as a form of rapidly clarifying whether or not the business idea is eligible for even preliminary evaluation without considerable investment of time and resources. In the process presented in figure 1, this activity is denominated informal screening. During the field study, five of the 12 new proposals presented were rejected as a result of informal screening.

This difference with regard to the interactive aspect of the decisionmaking process might be explained by the maturity and dimension of the private equity market. Contrarily to the situation in developed market contexts, in a market where a lack of knowledge about venture capital still exists, these early interactions are used by the VCF to inform the entrepreneurs about the functions and implications of venture capital financing, while at the same time eliminating the unsuitable proposals. These interactions are also used for gathering the basic information about the business idea, in particular, as an alternative to reading a formal business plan, which in the case of early-stage proposals in this market context often do not exist at the beginning of the investment process.

In the field study, it became evident that in the different phases of the decision-making process several activities were taking place simultaneously, rather than sequentially as it is represented in some of the previous models (e.g. Hall 1989). For instance, after the VCs' decision to proceed with the further investigation of the proposal (event 4), three activities were usually initiated simultaneously (see figure 1): the validation of information (due diligence), the collection of (further) information and the negotiations of the basic aspects of the deal terms with the entrepreneurs.

Concerning the differences associated with specific stage of decisionmaking process, the most relevant ones were found in the phases, stages or steps of the process generally regarded to as deal origination, deal evaluation and deal structuring phase (see, for example, Tyebjee and Bruno 1984). As to the deal origination phase, the evidence gathered in the field study points towards the existence of a signalling activity. Signalling was carried out by the VCF and consisted in pro-actively informing the potential entrepreneurs (in conferences or other public occasions/presentations) about venture capital and the type of business the VCF is looking for, in order to capture new valuable proposals. Aiming at capturing good business opportunities, the VCF under investigation also participated as a jury in business competitions and 
invested in business incubators. The observations clearly point to a rather significant active approach in the deal origination phase, instead of passively waiting for unsolicited or referred proposals. Such an active approach seems to result from a lack of a strong referral network (during the field study none of the 12 new proposals came from referred deals) that could present selected proposals to the VCF, as it usually happens in developed equity markets. The significant active approach (pro-active solicitations) in deal origination phase was also noted by Bliss (1999) in VCs' decision-making process of a transition economy, which also have a small equity market. Therefore, it seems reasonable to suggest that rather than being a characteristic of 'the unique economic conditions and operating environment in Poland' (Bliss 1999: 248), the difference can instead be due to the maturity of the equity market.

In the deal evaluation phase (located between the events 4 and 6 in figure 1), the observations and archival review carried out during the field study reveal that a proposal may go through several evaluation cycles. This happened in the situations when further validation or collection of information was needed before reaching an internal decision to invest (event 6), as well as in those situations when a syndication of equity financiers was required. Two promising but yet immature proposals under analysis had gone through several evaluation cycles and were reassessed in the light of modifications or development of the business idea. On the basis of observations and information obtained in informal conversations with $\mathrm{VCs}$, an explanation for the willingness of the $\mathrm{VCF}$ both, to wait for modifications or development of the business idea and to re-evaluate the proposal instead of simply rejecting the proposal, may once again be found in the maturity and dimension of the private equity market and, in particular, in the fact that in small markets interesting proposals do not abound.

The activities carried out by VCs in the last phase do not entirely correspond to those described in the models by Tyebjee and Bruno (1984), Hall (1989), and Boocock and Woods (1997). In the field study, an important activity, namely the negotiation of the deal terms, was normally initiated already during the evaluation phase. After the VCF internal decision to invest in the proposal (event 6 in figure 1), the main activity pursued is the negotiation of the contract terms, since at this stage the deal terms are nearly totally defined. These findings are consistent with the closing phase proposed by Fried and Hisrich (1994).

Regarding the decision-making criteria applied by the VCF, most of the observations during the study are in accordance with findings of the previous literature. The evidence collected indicates that VCs pay significant attention to the entrepreneur(s), placing a special focus on the knowledge or contacts (that add value for the business project) developed by the entrepreneurs in their previous jobs or in their research activity. In the screening stage, the curriculum vitae was an important source of information used by VCs to infer the value of entrepreneurs. During a formal screening meeting, one proposal was quickly rejected, since the credibility of the whole proposal was heavily affected by the fact that the information about the entrepreneurs was lacking. 
VCs also attempted to verify the degree of commitment of the entrepreneur(s). In the screening phase, the VCs tried to assess if the entrepreneurs were indeed presenting a great business idea and, hence, were willing to risk a currently stable or well-remunerated job or if they, instead, viewed the business proposed for financing merely as means of creating their own jobs.

Finally, during the interactions with entrepreneurs, VCs tried to understand whether or not the entrepreneurs had a thorough understanding of the business. For instance, have they conducted a basic preliminary market research? Have they considered the various risks and costs involved, and thought of the possible alternatives in case the original strategy fails?

With regard to the business idea, VCs seem to give preference to proposals in growing industries, rather than industries currently facing difficulties (e.g. e-businesses). Another interesting aspect verified in observation was that in the case of proposals concerning a consumer product, VCs role-played, using themselves or the people within the circles of their personal relations as potential customers, in order to evaluate the relevance of the new product. Furthermore, VCs seem to look for businesses with a reasonable growing potential. Although they did not exclude very small proposals from the analysis, VCs expressed serious concerns about investing in small businesses, as the resources required for monitoring and value adding the investment would be equal or superior to those involved in larger proposals. The sustainability of the competitive advantage of the business was also carefully examined, considering such aspects as the threat of new entrance, development of substitute products and the ability of the new firm to secure their value-added by protecting their innovations.

Contrary to the findings in the previous literature, financial projections were not considered essential in early-stage proposals. Being considered unreliable, financial projections were often used by $\mathrm{VCs}$ merely to estimate the break-even point of the company under analysis. As referred by Royer (2003: 56), 'clearly, any project has to start with faith because there typically isn't much objective evidence, if any, at the beginning to justify it. But, as a project unfolds and investment increase, this faith has to be increasingly tested against data'. The decision based on the 'faith' about the financial potential of the business idea held true for the only proposal over which the decision to invest was internally reached by the VCF during period of the field study. Since the investment required was not large, it was decided to invest in order to see the potential of the business and to eventually secure VCF's position in future rounds of financing.

\section{Conclusion}

Despite significant academic research undertaken in the field of venture capital decision-making process, the importance of such contextual factors as dimension and maturity of private equity market have not yet been 
considered. The instrumental case study of a Portuguese VCF presented in this article was an attempt to investigate this research gap. Adopting a processual perspective, the case study was focused on the first phase in the VC's decision-making cycle, namely, the investment process.

The discrepancies revealed in the case study concern the structure and the dynamics of decision-making process. First, the overall process was found to be more interactive than it is portrayed in the preceding VC's decision-making models. This difference may be explained by the maturity and dimension of the private equity market. Furthermore, some of the activities traditionally thought of as occurring sequentially, may actually be carried out simultaneously.

The discrepancies in particular stages of the process concern in particular the deal origination phase, where a significant pro-active behaviour of the VCF was observed; and the deal evaluation phase, in which an important difference found was willingness of the $\mathrm{VCF}$ to re-evaluate promising yet immature proposals. These phase-specific discrepancies may also be explained by the maturity of the private equity market. However, the dynamic observed in the deal evaluation phase may be due to the methodology applied in the previous studies. The most significant finding in the closing phase was that, contrarily to what is described in the majority of existing models, the negotiations of the deal terms are completed but not initiated in this phase. Instead, this activity was already initiated in the evaluation phase.

Finally, regarding the decision-making criteria applied by the $\mathrm{VCF}$, most of the observations during the study are in accordance with findings of the previous literature. VCs' attention is indeed very much focused on entrepreneur(s), their personal and professional characteristics and their commitment to the business idea. Additionally, VCs tend to assess carefully the business idea, its growing potential as well as the sustainability of its competitive advantages. However, contrarily to findings in the previous literature, the observations in the field study suggest that the financial projections do not play such an important decision factor for early-stage proposals.

\section{Acknowledgements}

The author would like to thank the management team and staff of the venture capital firm where the participant observation was conducted for their cooperation, Professor Matti Koiranen for his encouragement and guidance, and the participants of the Venture Capital Track at the 48th ICSB World Conference in 2003 for their helpful comments. Thanks also to Professor Colin Mason and an anonymous reviewer whose incisive comments and suggestions improved this paper significantly.

\section{Note}

1. Early stage proposals refer to proposals in seed or start-up stage. 


\section{References}

Becker, H., 1958, Problems of inference and proof in participant observation. American Sociological Review, 23, 652-660.

Bliss, R. T., 1999, A venture capital model for transitioning economies: the case of Poland. Venture Capital: An International Fournal of Entrepreneurial Finance, 1, 241-257.

Boocock, G. and Woods, M., 1997, The evaluation criteria used by venture capitalists: evidence from a UK venture fund. International Small Business Fournal, 16, 36-57.

Ericsson, K. A. and Simon, H. A., 1984, Protocol Analysis: Verbal Protocols as Data (Cambridge, MA: MIT Press).

Fried, V. H. and Hisrich, R. D., 1994, Toward a model of venture capital investment decision making. Financial Management, 23, 28-37.

Hall, H. J. and Hofer, C. W., 1993, Venture capitalists' decision criteria and new venture evaluation. Fournal of Business Venturing, 8, 25-42.

Hall, H. J., 1989, Venture capital decision making and the entrepreneur: an exploratory investigation, unpublished doctoral thesis, University of Athens, Georgia.

Jorgensen, D. L., 1993, Participant Observation (London: Sage Publications).

Karsai, J., Wright, M., and Filatotchev, I., 1997, Venture capital in transition economies. The case of Hungary. Entrepreneurship Theory and Practice, Summer, 93-110.

Khan, A. M., 1987, Assessing venture capital investments with non-compensatory behavioral decision Models. Fournal of Business Venturing, 2, 193-205.

Knight, R. M., 1994, Criteria used by venture capitalists: a cross cultural analysis. International Small Business Fournal, 13, 26-37.

MacMillan, I. C., Siegel, R. and Subba Narasimha, P. N., 1985, Criteria used by venture capitalists to evaluate new venture proposals. Fournal of Business Venturing, 1, 119-128.

MacMillan, I. C., Zemann, L. and Subba Narasimha, P. N., 1987, Criteria distinguishing successful from unsuccessful ventures in the venture screening process. Fournal of Business Venturing, 2, $123-137$.

Muzyka, D., Birley, S. and Leleux, B., 1996, Trade-offs in the investment decisions of european venture capitalists. Fournal of Business Venturing, 11, 273-287.

Pettigrew, A. M., 1997, What is a processual analysis? Scandinavian fournal of Management, 13, 337 348.

Poindexter, E. A., 1976, The efficiency of financial markets: the venture capital case, unpublished doctoral dissertation, New York University, New York.

Riquelme, H. and Rickards, T., 1992, Hybrid conjoint analysis: an estimation probe in the new venture decisions. Fournal of Business Venturing, 7, 505-518.

Royer, I., 2003, Why bad projects are so hard to kill. Harvard Business Review, 81, 49-56.

Ruhnka, J. C. and Young, J. E., 1987, A venture capital model of the development process for new ventures. Fournal of Business Venturing, 2, 167-184.

Sandberg, W. R., Schweiger, D. M. and Hofer, C. W., 1988, The use of verbal protocols in determining venture capitalists' decision process. Entrepreneurship Theory and Practice, Winter, 8-20.

Shepherd, D. A., 1999, Venture capitalists' introspection: a comparison of 'in use' and 'espoused' decision policies. Fournal of Small Business Management, April, 76-87.

Silver, A. D., 1985, Venture Capital: The Complete Guide for Investors (New York: John Wiley and Sons).

Stake, R. E., 1995, The Art of Case Study Research (London: SAGE Publications).

Tan, W.-L., 1997, Investment criteria of Singapura venture capitalists. Conference Proceedings of the $42^{\text {nd }}$ World Conference ICSB, San Francisco.

Timmons, J. and Gumpert, D., 1982, Discart many old rules about getting venture capital. Harvard Business Review, 60, 273-280.

Tyebjee, T. T. and Bruno, A. V., 1981, Venture capital decision making. In K.H. Vesper (ed.) Frontiers of Entrepreneurship Research (Wellesley, MA: Babson College), $281-320$.

Tyebjee, T. T. and Bruno, A. V., 1984, A model of venture capitalist investment activity. Management Science, 30, $1051-1066$. 
Wells, W. A., 1974, Venture capital decision making, unpublished doctoral dissertation, Carnegie Mellon University, Pittsburgh.

Zacharakis, A. L. and Meyer, G. D., 1998, A lack of insight: do venture capitalists really understand their own decision process? Fournal of Business Venturing, 13, 57-76.

\section{Appendix 1}

Source of evidence

\begin{tabular}{|c|c|c|}
\hline Type & Code & Description \\
\hline \multirow[t]{7}{*}{$\overline{\text { Observations }}$} & O1 & $\begin{array}{l}\text { telephone conversation(s) between investment analyst and an } \\
\text { entrepreneur }\end{array}$ \\
\hline & $\mathrm{O} 2$ & telephone conversation(s) between investment analyst and an expert \\
\hline & $\mathrm{O} 3$ & meeting(s) between representatives of the VCF and entrepreneur(s) \\
\hline & $\mathrm{O} 4$ & executive meeting(s) were the proposal was discussed \\
\hline & O5 & VCF's weekly meeting(s) of decision makers \\
\hline & O6 & informal discussions between investment analyst(s) and executive(s) \\
\hline & O7 & participation of VCF's representatives as conference speakers \\
\hline \multirow[t]{2}{*}{ Interviews } & I1 & informal discussions with investment analyst(s) and/or executive(s) \\
\hline & I2 & $\begin{array}{l}\text { standardised open-end interview with investment analyst(s) and } \\
\text { executive(s) }\end{array}$ \\
\hline \multirow[t]{18}{*}{ Documents } & D1 & $\begin{array}{l}\text { correspondence (letters and/or e-mails) exchanged with the entre- } \\
\operatorname{preneur(s)}\end{array}$ \\
\hline & D2 & investment analysts' notes regarding the proposal \\
\hline & D3 & draft of the business idea \\
\hline & D4 & business plan \\
\hline & D5 & preliminary report produced by the investment analyst \\
\hline & D6 & in-depth report(s) produced by the investment analyst \\
\hline & D7 & $\begin{array}{l}\text { drafts of the legal documents (shareholder agreement and articles of } \\
\text { association) }\end{array}$ \\
\hline & D8 & drafts of the deal structure \\
\hline & D9 & legislation regulating $\mathrm{VC}$ activity in Portugal \\
\hline & D10 & article(s) in press \\
\hline & D11 & internet search results \\
\hline & D12 & memos of executive meetings \\
\hline & D13 & $\begin{array}{l}\text { results of the participation of VCF's representative as member of } \\
\text { jury in a business plan competition }\end{array}$ \\
\hline & D14 & PowerPoint presentations of VCF's representatives for conferences \\
\hline & D15 & $\begin{array}{l}\text { plans of participations of VCF's representatives as conference } \\
\text { speakers }\end{array}$ \\
\hline & D16 & VCF's archives of proposals rejected and accepted \\
\hline & D17 & VCF's press releases \\
\hline & D18 & VCF's annual reports \\
\hline
\end{tabular}




\section{Appendix 2}

EVIDENCE GATHERED REGARDING ACTIVITIES AND EVENTS (BY SOURCE)-PROPOSAL 1 TO 8

\begin{tabular}{|c|c|c|c|c|c|c|c|c|c|}
\hline & \multirow[b]{2}{*}{ Activities and Events } & \multicolumn{8}{|c|}{ Proposals } \\
\hline & & 1 & 2 & 3 & 4 & 5 & 6 & 7 & 8 \\
\hline & Venture Capital Firm Signalling & & & & D13, I1, I2 & & & & \\
\hline & Entrepreneurs' Informal Contact & & & D2, I1 & & D1 & D1 & D1 & \\
\hline & Informal Screening 1 & & & & & $\mathrm{O} 1, \mathrm{O} 5$ & D1 & $\mathrm{D} 2, \mathrm{O} 3$ & \\
\hline \multirow[t]{3}{*}{ or } & $\begin{array}{l}\text { Entrepreneurs' Formal Contact } \\
\text { Proposal Rejected }\end{array}$ & D4 & D3 & & D4 & D3 & D1, I1, I2 & D4 & D1, D3 \\
\hline & Collection of Information 1 & D2 & D2 & D1 & & $\mathrm{O} 2$ & & D1, D11 & D2, D10, D11 \\
\hline & Informal Screening 2 & & & & & O6 & & D1, I1 & \\
\hline \multirow[t]{2}{*}{ or } & $\begin{array}{l}\text { Preliminary Report } \\
\text { Proposal Rejected }\end{array}$ & D5 & D5 & D5 & D5 & D1, I1, I2 & & D5, I1 & D5, I1 \\
\hline & Formal Screening Meeting & & & & & & & $\mathrm{O} 4$ & $\mathrm{O} 4$ \\
\hline \multirow[t]{6}{*}{ or } & $\begin{array}{l}\text { Decision to Investigate Further } \\
\text { Proposal Rejected }\end{array}$ & D12, I2 & D12, I1 & D12, I1, I2 & D12 & & & $\mathrm{D} 12, \mathrm{I} 2$ & D12, I2 \\
\hline & Validating Information & & D1, I1 & D1, I1 & D1 & & & D1, O5 & \\
\hline & Collecting Information 2 & D2, D10 & D2, D4 & D2, D10, I1 & D2, D10 & & & D2, D11, O5 & \\
\hline & Negotiating Deal Terms 1 & & D2, D8 & & & & & D2 & \\
\hline & In-Depth Report & D6 & D6 & & D6 & & & D6 & \\
\hline & Evaluating Meeting & D12 & D12 & & D12, I1 & & & & \\
\hline \multirow[t]{3}{*}{$\begin{array}{l}\text { or } \\
\text { or }\end{array}$} & $\begin{array}{l}\text { Internal Decision to Invest } \\
\text { Decision to Investigate Further } \\
\text { Proposal Rejected }\end{array}$ & $\mathrm{D} 1, \mathrm{I} 1, \mathrm{I} 2$ & $\mathrm{D} 1, \mathrm{I} 1, \mathrm{I} 2$ & & $\mathrm{I} 1, \mathrm{I} 2$ & & & & \\
\hline & Negotiating Contract Terms & & & & D7, O3, O6 & & & & \\
\hline & Negotiating Deal Terms 2 & & & & D8, O3, O6 & & & & \\
\hline or & $\begin{array}{l}\text { Venture Capital Investment } \\
\text { Proposal Rejected }\end{array}$ & & & & & & & & \\
\hline
\end{tabular}

Note: The sources of evidence listed in this appendix are presented by their code. See Appendix 1 for their description. 


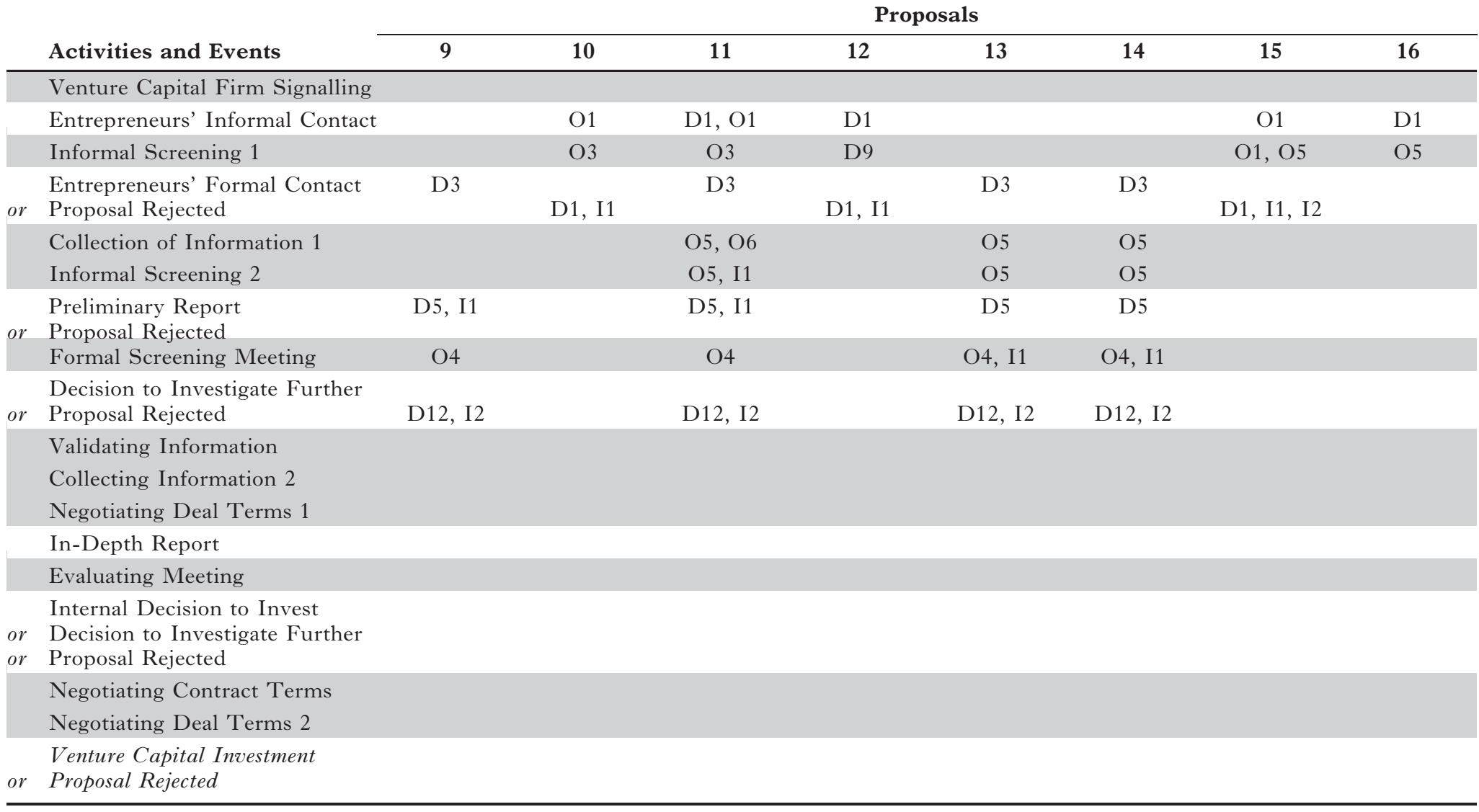


PHASE

\begin{tabular}{|c|c|c|c|c|c|}
\hline Code & CRITERIA OBSERVED ${ }^{\text {a) }}$ & Informal Screening & Formal Screening & Evaluation & Closing \\
\hline \multirow[t]{7}{*}{$\overline{\mathrm{CE}}$} & Regarding the entrepreneur(s): & & & & \\
\hline & Entrepreneur's Education & Proposals 5, 11 & Proposals 1, 2, 4, 7, 11 & & \\
\hline & Entrepreneur's Management Skills & Proposal 5 & Proposals $1,2,3,4$ & & Proposal 4 \\
\hline & Entrepreneur's Knowledge of the Business & Proposal 7 & Proposals 1, 2, 3, 4, 7, 9 & & \\
\hline & Entrepreneur's Track Record & Proposals 7,11 & Proposals $1,2,3,7,9,11$ & & \\
\hline & Entrepreneur's Commitment to the Project & Proposal 7 & Proposals 3,7 & Proposal 7 & Proposal 4 \\
\hline & Entrepreneur's Personality & Proposal 5 & Proposal 3 & & \\
\hline \multirow[t]{5}{*}{ CB } & Regarding the business idea: & & & & \\
\hline & Time to Market & Proposal 5 & Proposal 1 & Proposal 1 & \\
\hline & Level of Innovation & Proposals 7, 10 & Proposals $1,4,8,9$ & & \\
\hline & Growth Potential & Proposals 7, 10, 11, 15, 16 & Proposals $1,2,3,4,7,11$ & Proposal 7 & \\
\hline & Value Added & Proposal 15 & Proposals 13,14 & & \\
\hline \multirow[t]{7}{*}{ CM } & Regarding the market: & & & & \\
\hline & Size of Market & Proposal 5 & Proposals 1,2 & & \\
\hline & Industry Situation & Proposals 6, 16 & Proposals $3,13,14$ & Proposal 3 & \\
\hline & Substitute Products & & Proposals $1,7,9$ & & \\
\hline & Entry Barriers & & Proposals 7, 9 & & \\
\hline & Level of Competition in Industry & & Proposals 8,14 & & \\
\hline & Access to Distribution Channel & & Proposal 8 & Proposals 2, 7 & \\
\hline \multirow[t]{5}{*}{ CD } & Regarding the deal proposed to VCF: & & & & \\
\hline & Valuation & Proposals 6,7 & Proposal 1 & & \\
\hline & Capacity to Obtain Complementary Financing & & Proposal 1 & Proposal 1 & \\
\hline & Absolute Investment Size & Proposal 6 & Proposals 11, & Proposal 4 & \\
\hline & Sinergy with Current Investees of the VCF & & Proposals 13,14 & & \\
\hline \multirow[t]{2}{*}{$\mathrm{CO}$} & Others: & & & & \\
\hline & Legal Restrictions & Proposal 12 & & & \\
\hline
\end{tabular}

a) Since the proposals 1 to 4 where already under analysis at the time the field study was started, the criteria presented in this table regarding these proposals are mainly extracted from reports and notes written by the investor analysts. 
Copyright of Venture Capital is the property of Taylor \& Francis Ltd and its content may not be copied or emailed to multiple sites or posted to a listserv without the copyright holder's express written permission. However, users may print, download, or email articles for individual use. 